\title{
QUALITY ASSESSMENT BASED ON ACCURATE POSITIONING PRODUCTION RESULTS OF NATIONAL GEOMORPHIC DATA
}

\author{
YIN Su*, ZHANG Li, ZHAO Hai Tao, CHEN Hai Peng, GAO Wen Chao
}

National Quality Inspection and Testing Center for Surveying and Mapping Products, 28 West Lianhuachi Road, Beijing, China

\author{
Commission III
}

KEY WORDS: Geomorphic Data, Quality Assessment, Accurate Positioning

\begin{abstract}
:
Using high-precision DEM and high-resolution image, the geomorphic type boundary is accurately located on the basis of 1:1 million geomorphic type data boundary in China. For the first time, a national geomorphic data set with positioning accuracy of 1:250000 scale mapping accuracy has been formed. Based on the production technology and process of 1:250000 national geomorphic data set, as well as the content index and requirement of geomorphic statistical analysis, this paper designs and realizes the quality inspection model, evaluation index and evaluation method of 1:250000 national geomorphic data set. The results of 60 1:250000 geomorphic data as samples show that the quality of geomorphic data can be truly reflected.
\end{abstract}

\section{INTRODUCTION}

Geomorphology is a general term for all kinds of undulating forms of the earth's land surface and seafloor. It is a synthesis of the morphological characteristics, genetic types, distribution patterns and development process of the earth's land surface and seafloor. Geomorphic form, geomorphic type and geomorphic process determine the type and distribution of ecological environment and resources, as well as the way and degree of utilization. Geomorphology affects the formation, total amount, distribution and change of water resources. Therefore, the comprehensive analysis of the geomorphic characteristics has an important basic role in the study of the formation and evolution of the ecological environment and natural resources, and has practical guiding significance for the understanding, development and protection of natural resources.

The national 1:250000 geomorphic type data set is based on the national 1:1 million digital geomorphic type data results, taking the multi-source aerospace remote sensing image better than 1 meter as the main data source, creating a high-precision geomorphic data set, storing attribute information, geomorphic type code and name after the precise location of geomorphic type unit (Zhao Rong, 2019).

\section{ACCURATE POSITIONING OF GEOMORPHIC DATA CHARACTERISTICS}

\subsection{Data Characteristic}

The geomorphic type unit data is organized by 1:250000 maps. Based on the results of 1:1 million digital geomorphic type data, with reference to high-precision DEM, high-resolution image and other basic geographic information, the boundaries of geomorphic types are precisely located by interactive way, forming a national 1:250000 geomorphic type data set (Zhou Chenghu, 2009).

\subsection{Technical Requirements}

The following technical indicators are adopted for the precise positioning of geomorphic type units (Zhao Wei, 2016):

(1) Plane position accuracy

The revised boundary of geomorphic type should be similar to the boundary of 1:1 million in general, and the combined error of geomorphic marker line (piedmont line, slope fold line, valley line) acquired based on DEM and geomorphic boundary line (structure, texture) acquired based on the difference line of orthophoto Image should be controlled within $75 \mathrm{~m}$ of the field. (2) Minimum map spot area of geomorphic type unit

The minimum map area of geomorphic type unit mainly refers to the control area of the minimum map area of platform, hill, peak forest and peak cluster in plain and karst area. The field area corresponding to the minimum map spot of geomorphic type unit is $1 \mathrm{~km}^{2}$, and the map spot with the field area larger than $1 \mathrm{~km}^{2}$ in general area shall be collected, and the map spot with the field area smaller than $1 \mathrm{~km}^{2}$ shall not be collected; the field area corresponding to the minimum map spot in special area (loess area, karst area) is $0.5 \mathrm{~km}^{2}$.

(3) Minimum width of belt geomorphic type unit

The minimum width of zonal geomorphic type unit is the control parameter for the width of valley plain. The minimum width of the banded geomorphic type corresponds to a field distance of $125 \mathrm{~m}$. The banded geomorphic type units with width greater than $125 \mathrm{~m}$ shall be indicated, and those with width less than $125 \mathrm{~m}$ shall not be indicated generally, but for important rivers or special areas, the banded geomorphic type units with width less than $125 \mathrm{~m}$ can be expanded to $125 \mathrm{~m}$.

(4) Minimum pattern spacing

The minimum distance between geomorphic units is $125 \mathrm{~m}$. Similar patterns with spacing less than $125 \mathrm{~m}$ can be combined (lakes, islands, sandbars are not combined, collinear representation), and different patterns can be collinear representation.

(5) Minimum curvature of geomorphic unit boundary

If the curvature of geomorphic type unit boundary is less than $200 \mathrm{~m} \times 200 \mathrm{~m}$, it can be properly simplified. The characteristic

\footnotetext{
* Corresponding author
} 
curvature should be exaggerated to $200 \mathrm{~m} \times 200 \mathrm{~m}$, but the shape similarity before and after synthesis should be maintained.

\section{INSPECTION CONTENTS AND EVALUATION}

\subsection{Inspection Contents}

Taking into account the characteristics of geomorphic type data and inspection efficiency and other factors, the contents and methods of accurate positioning production results of national geomorphic data are shown in Table 1 below.

\begin{tabular}{|c|c|c|}
\hline Quality element & Mass subelement & Check item \\
\hline \multirow{4}{*}{$\begin{array}{c}\text { Spatial reference } \\
\text { system }\end{array}$} & Geodetic datum & Coordinate system \\
\cline { 2 - 3 } & Elevation datum & Elevation datum \\
\cline { 2 - 3 } & Map projection & Projection parameter \\
\hline \multirow{4}{*}{ Logical consistency } & \multirow{2}{*}{$\begin{array}{c}\text { Conceptual } \\
\text { consistency }\end{array}$} & Attribute item \\
\cline { 3 - 3 } & \multirow{3}{*}{ Format consistency } & Data set \\
\cline { 2 - 3 } & & Data format \\
\cline { 3 - 3 } & \multirow{2}{*}{$\begin{array}{c}\text { Topological } \\
\text { consistency }\end{array}$} & Data file \\
\cline { 3 - 3 } & & File naming \\
\cline { 3 - 3 } & \multirow{2}{*}{ Plane accuracy } & Surface overlap \\
\cline { 3 - 3 } & & Continuity \\
\hline \multirow{2}{*}{ Position accuracy } & Boundary precision \\
\hline Attribute accuracy & Property correctness & Attribute value \\
\hline Completeness & Omission & Missing elements \\
\hline \multirow{2}{*}{ Accessory quality } & \multirow{2}{*}{ Metadata } & Missing entries \\
\cline { 3 - 3 } & & Content error \\
\hline
\end{tabular}

Table 1. Contents and methods of accurate positioning production results of national geomorphic data

\subsection{Evaluation Method}

Accurate positioning of national geomorphic data quality assessment of production results of units adopts qualified and unqualified assessment. The inspection items, quality sub elements and quality elements shall be scored according to the quality evaluation index, and the score shall not be calculated for the quality of unit results. When the scores of all quality elements are greater than or equal to 60 , the quality of unit achievement is judged as qualified; otherwise, the quality of unit achievement is judged as unqualified.

\subsection{Quality Assessment}

According to the quality evaluation model, the larger the error rate is, the more elements are allowed to be missed. The total number of elements of unit achievement is calculated by the mathematical number of all elements in the data, taking $1 \%$ to $5 \%$. Through the test statistical results, the evaluation results obtained at that time basically reflect the quality of achievements. In consideration of two special situations: (1) beyond the basic morphological type of landform; (2) special difficult areas such as Southeast hills, southwest karst, northwest desert, etc., the index of 2 times of the specified inspection items shall be relaxed for scoring. The quality scoring method of national geomorphic data results is shown in Table 2 below.

\begin{tabular}{|c|c|c|}
\hline Check item & Inspection contents & $\begin{array}{c}\text { Technical } \\
\text { requirement }\end{array}$ \\
\hline $\begin{array}{c}\text { Coordinate } \\
\text { system }\end{array}$ & $\begin{array}{c}\text { Check whether the coordinate } \\
\text { system meets the requirements }\end{array}$ & \\
\hline
\end{tabular}

\begin{tabular}{|c|c|c|}
\hline Elevation datum & $\begin{array}{l}\text { Check whether the elevation } \\
\text { datum meets the requirements }\end{array}$ & \multirow{2}{*}{$\begin{array}{l}\text { According to } \\
\text { the technical } \\
\text { design }\end{array}$} \\
\hline $\begin{array}{l}\text { Projection } \\
\text { parameter }\end{array}$ & $\begin{array}{l}\text { Check whether the parameters of } \\
\text { map projection meet the } \\
\text { requirements }\end{array}$ & \\
\hline Attribute item & $\begin{array}{l}\text { Check whether the property item } \\
\text { definition meets the requirements } \\
\text { (such as name, type, length, } \\
\text { sequence number, etc.) }\end{array}$ & \multirow{2}{*}{$\begin{array}{c}\text { According to } \\
\text { the technical } \\
\text { design }\end{array}$} \\
\hline data set & $\begin{array}{l}\text { Check whether the data set } \\
\text { (layer) definition meets the } \\
\text { requirements }\end{array}$ & \\
\hline data format & $\begin{array}{l}\text { Check whether the data file } \\
\text { format meets the requirements }\end{array}$ & \multirow{3}{*}{$\begin{array}{c}\text { According to } \\
\text { the technical } \\
\text { design }\end{array}$} \\
\hline data file & $\begin{array}{l}\text { Check whether the data file is } \\
\text { missing and the data cannot be } \\
\text { read out }\end{array}$ & \\
\hline File naming & $\begin{array}{l}\text { Check whether the data file name } \\
\text { meets the requirements }\end{array}$ & \\
\hline Face gap & Check if there is any spot gap & \multirow{3}{*}{$\mathrm{r}_{0}=3 \%$} \\
\hline Surface overlap & Check for pattern overlap & \\
\hline continuity & $\begin{array}{l}\text { Check the number of errors of } \\
\text { discontinuous elements }\end{array}$ & \\
\hline $\begin{array}{l}\text { Boundary } \\
\text { precision }\end{array}$ & $\begin{array}{l}\text { Check the number of elements } \\
\text { that are out of limit when they are } \\
\text { combined with digital elevation } \\
\text { model, image and other data }\end{array}$ & \multirow[t]{2}{*}{$\mathrm{r}_{0}=3 \%$} \\
\hline $\begin{array}{l}\text { Vector Edge } \\
\text { Matching }\end{array}$ & $\begin{array}{l}\text { Check the number of features } \\
\text { whose geometric position edge } \\
\text { exceeds the limit }\end{array}$ & \\
\hline Attribute value & $\begin{array}{l}\text { Check the number of errors and } \\
\text { omissions of the feature } \\
\text { classification code value, } \\
\text { including the error that the } \\
\text { feature classification code value } \\
\text { is not connected. The number of } \\
\text { faults and omissions beyond the } \\
\text { basic morphological type of } \\
\text { landform is } 1 \text { fault for every } 2 \\
\text { places. }\end{array}$ & $\mathrm{r}_{0}=3 \%$ \\
\hline $\begin{array}{l}\text { Missing } \\
\text { elements }\end{array}$ & $\begin{array}{l}\text { Check the number of missing } \\
\text { elements. The number of errors } \\
\text { and omissions in the southeast } \\
\text { hills, southwest karst, northwest } \\
\text { desert and other special difficult } \\
\text { areas is } 1 \text { for every } 2 \text { places. }\end{array}$ & $\mathrm{r}_{0}=5 \%$ \\
\hline Missing entries & $\begin{array}{l}\text { Check the number of errors and } \\
\text { omissions of metadata items }\end{array}$ & $\begin{array}{l}\text { According to } \\
\text { the technical } \\
\text { design }\end{array}$ \\
\hline Content error & $\begin{array}{l}\text { Check the number of errors and } \\
\text { omissions in each content of } \\
\text { metadata }\end{array}$ & $\mathrm{r}_{0}=5 \%$ \\
\hline
\end{tabular}

Table 2. Quality evaluation indexes of accurate positioning production results of national geomorphic data

The scoring method of quality element $\mathrm{s}$ is calculated according to formula (1).

$$
s=60+40 / \mathrm{r}_{0} \times\left(\mathrm{r}_{0}-r\right)
$$

where $\quad s=$ quality element score

$\mathrm{r}_{0}=$ error rate limit

$r=$ error rate

The scoring method of the error rate $r$ is calculated according to formula (2).

$$
r=n / N \times 100 \%
$$

where $\quad r=$ error rate

$n=$ total number of errors

$N=$ total number of elements 


\section{PROBLEMS AND ANALYSIS}

\subsection{Sample Quality Evaluation}

In the experiment, 60 1:250000 geomorphic data results are selected as detailed investigation samples. Through the detailed investigation of the samples and the general investigation of the rest of the maps, it is found that there are still some problems in the data results, such as the positioning error of the geomorphic boundary, the positioning accuracy is not enough, the attribute of the geomorphic type is not correct, the border of the map is wrong and the metadata is not standardized. Taking the position accuracy, attribute accuracy and integrity as the statistical indicators, the sample quality distribution is shown in the Figure 1 below.
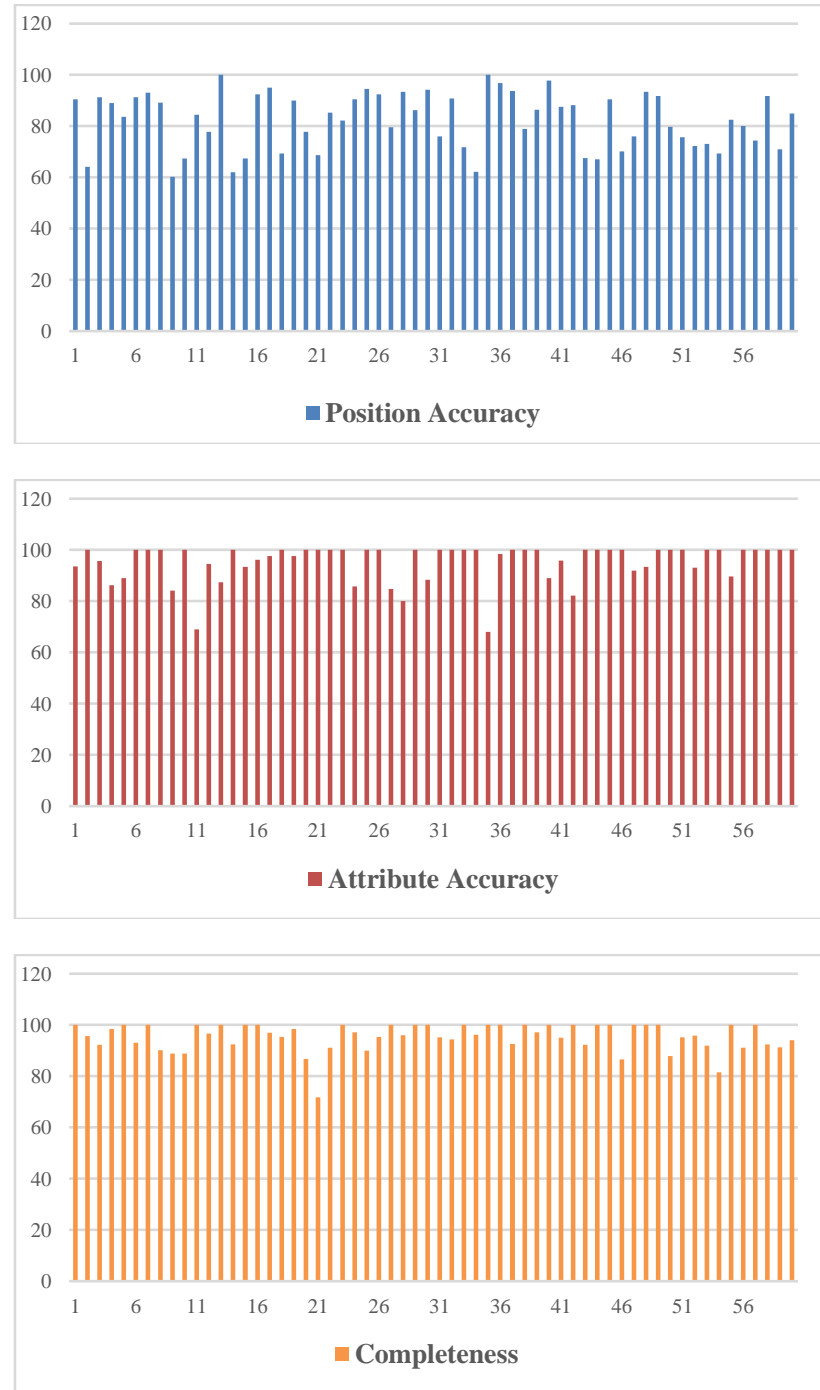

Figure 1. Sample mass distribution

\subsection{Common quality problems and analysis}

The analysis and discussion of common problems are as follows: Figure 2 shows the typical problems of plane accuracy. Among them, (a) is the over limit of the fitting error of the geomorphic boundary line. According to the requirements of the technical design, the error of the fitting error of the collected geomorphic boundary line should be controlled within $75 \mathrm{~m}$ of the field. It can be seen that on the basis of reference 1:1 million geomorphic type data, where the difference between geomorphic boundary and DEM gray shading map is more than twice of the mean square error, the geomorphic boundary line is not located and collected; (b) the geomorphic boundary line is inconsistent with the reference data, and it can be seen that where the geomorphic boundary line (such as Lake) is inconsistent with the reference data; (c) the geomorphic boundary line is inconsistent with the reference data The boundary line is not connected; (d) the geomorphic boundary line is unreasonable.

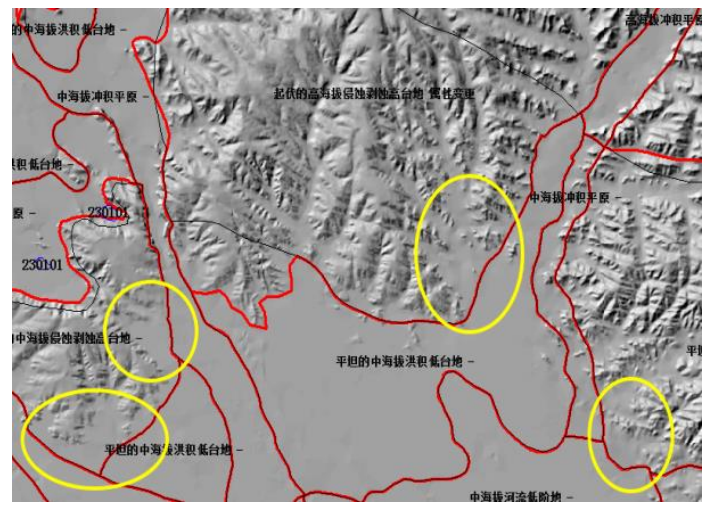

(a) Geomorphic boundary line overlap out of limit

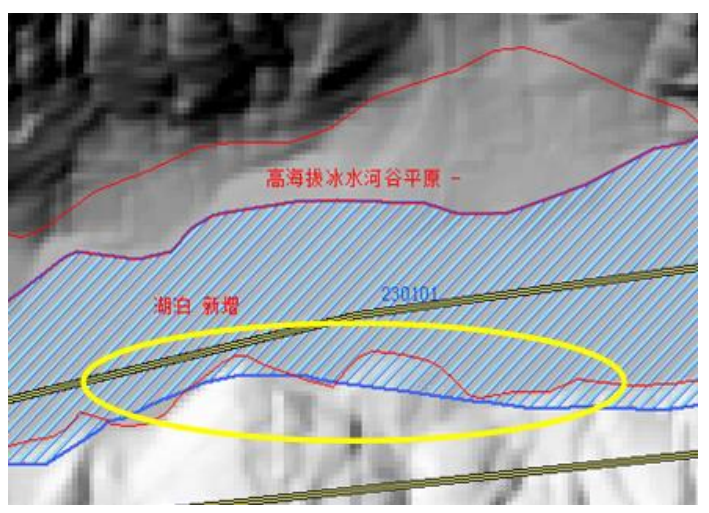

(b) Boundary line inconsistent with reference data

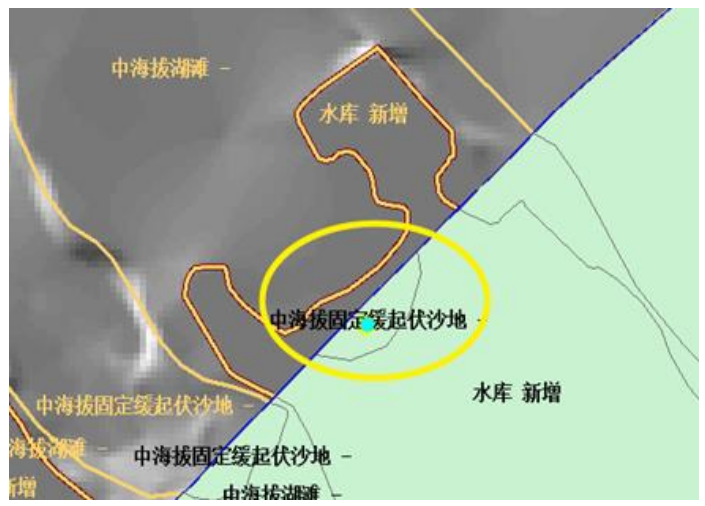

(c) Boundary line not connected 


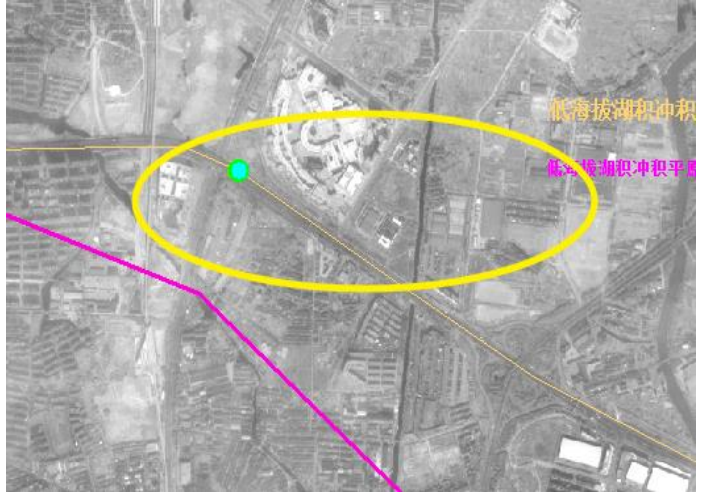

(d) Unreasonable boundary line

Figure 2. Analysis of plane accuracy

Figure 3 shows the typical problems of attribute accuracy. Among them, (a) is the attribute error of the newly added geomorphic type unit; (b) is that the geomorphic type unit is inconsistent with the reference data.

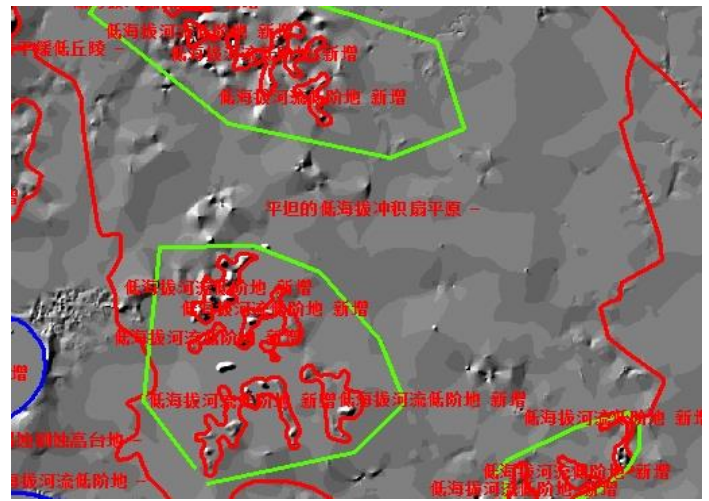

(a) Attribute error for new geomorphic type unit

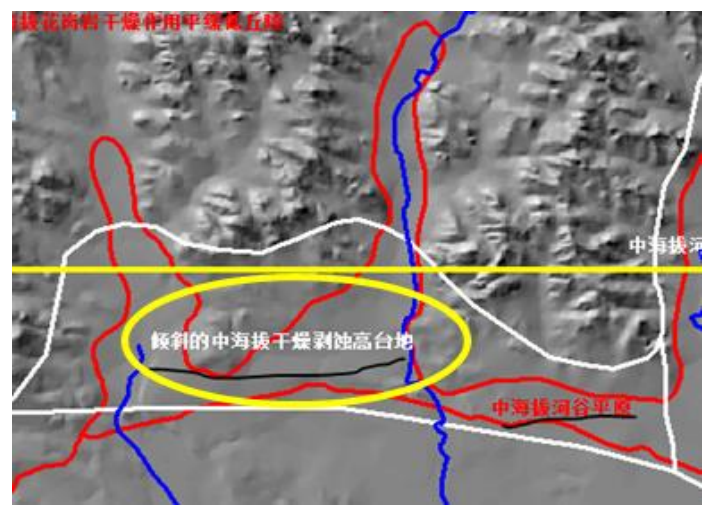

(b) Inconsistent with reference data attributes

Figure 3. Analysis of attribute accuracy

Figure 4 is a typical problem of element omission. Among them, (a) refers to the omission of reference 1:1 million geomorphic type units. It can be seen that based on the reference 1:1 million geomorphic type data, the above map spots have not been collected; (b) refers to the omission to collect enough index map spots. According to the requirements of technical design, the minimum field area corresponding to the map spots of geomorphic type units is $1 \mathrm{~km}^{2}$. It can be seen that compared with
1:1 million geomorphic type data, there are spots (such as alluvial plain) with a field area greater than $1 \mathrm{~km}^{2}$ which have not been collected.

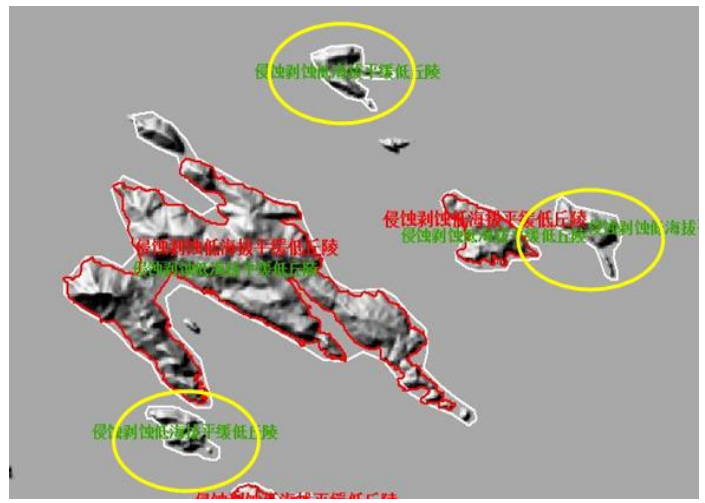

(a) Missing reference 1:1 million geomorphic type unit

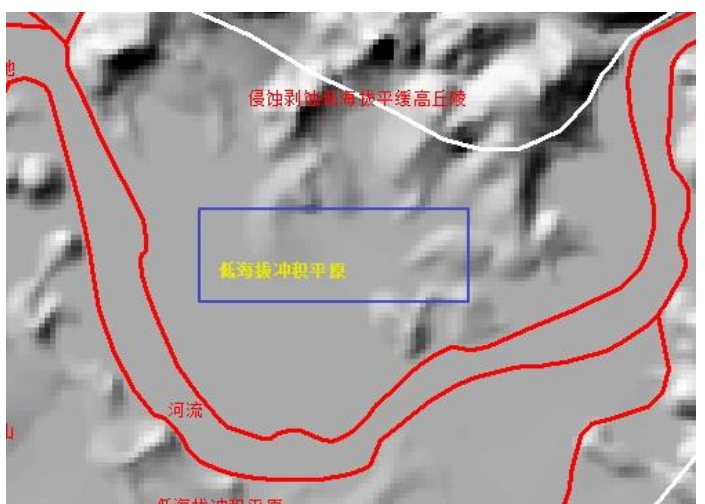

(b) Missing enough index map spots

Figure 4. Integrity analysis

\section{CONCLUSION}

This paper analyzes the content and characteristics of the national geomorphic data set of 1:250000 scale mapping accuracy in China. Based on the three-level quality model of quality elements, sub elements and inspection items, a quality inspection model suitable for the national geomorphic data set is proposed, and the content, index and method of quality inspection of the data set are determined, which provides the quality for the domestic geomorphic base of China. It can provide reference for the quality inspection of higher precision geomorphic types.

\section{REFERENCES}

China Academy of Surveying and mapping, 2013: Atlas of Typical Landforms in Western China. China Map Press.

Editorial board of geomorphological atlas, Chinese Academy of Sciences, 2009: Geomorphological Atlas of the people's Republic of China 1:1 million. Science Press.

G Bocco, M Mendoza, A Velázquez, 2001. Remote sensing and GIS-based regional geomorphological mapping-a tool for land use planning in developing countries. Geomorphology, 39 (3), 211-219. 
M.J. Smith,J. Rose,S. Booth, 2005. Geomorphological mapping of glacial landforms from remotely sensed data: An evaluation of the principal data sources and an assessment of their quality. Geomorphology, 76(1).

Zhou Chenghu, Cheng Weiming, Qian Jinkai, Li Bingyuan, Zhang Baiping, 2009. Study on the 1:1 million digital geomorphological classification system of China land. Journal of Earth Information Science, 11 (06), 707-724.

Zhou Chenghu, 2009: Remote sensing analysis and mapping of digital landforms. Science Press.

Zhao Rong, Cheng Weiming, Liu Jiping, Dong Chun, Yu ronghua, Yin Hongmei, 2019. Classification of high-precision land geomorphic types in China. Surveying and Mapping Science, 44 (06), 248-255.

Zhao Wei, Lu Di, Li Hongwen, 2016. Discussion on accurate positioning of geomorphic type data. Standardization of Surveying and mapping, 32 (03), 22-24. 